\title{
Dissolving oxygen in diesel fuel as a way to make road transport more environmentally friendly
}

\author{
J. Merkisz, M. Bajerlein \& W. Kozak \\ Institute of Combustion Engines and Transport, \\ Poznan University of Technology, Poland
}

\begin{abstract}
The Institute of Combustion Engines and Transport has developed a concept of fuelling diesel engines with an improved mechanism of spray. The proposed novelty value of spray consists in dissolving either air, exhaust gases or oxygen in diesel fuel.

The effervescence of diesel fuel mixed with gases is to facilitate the spray. In the non-equilibrium states of a solution, formed as a result of dissolving gas in a liquid, the gaseous phase is spontaneously released from the solution. This process has a volumetric character and at the appropriate kinetics it is strong enough to be accompanied by the effervescence (bubbling) of the liquid. At the moment, widespread researches are carried out in order to evaluate the practical application of the concept in injection systems. This article presents the results of tests concerning the impact of oxygen dissolved in diesel fuel on the combustion process in diesel engines. The tests were done in the piston head of an engine equipped with a toroidal combustion chamber and direct injection. During the tests the following factors were measured: the main indicators of motor operation, the range of pressure values obtained in the combustion chamber and before the injector, emissions of $\mathrm{HC}, \mathrm{CO}_{2}, \mathrm{CO}, \mathrm{NO}_{\mathrm{x}}$ and opacity.
\end{abstract}

Keywords: CI engine, alternative fuels, emissions, dissolving process.

\section{Introduction}

Combustion processes that occur in a compression-ignition engine (CI) as the outcome of direct injection are of a special nature owing to the fact that liquid 
fuel in the form of fuel sprays is supplied to the engine combustion chamber right before the piston top dead centre (TDC). Thus pretreatment of the fuel mixture before burning, which includes for instance fuel spray disintegration into droplets or evaporation and mixing with air, is constrained in a very short time. This way of fuelling the engine entails significant local differences between the excess air factor values $\lambda$ in various areas (fig. 1).

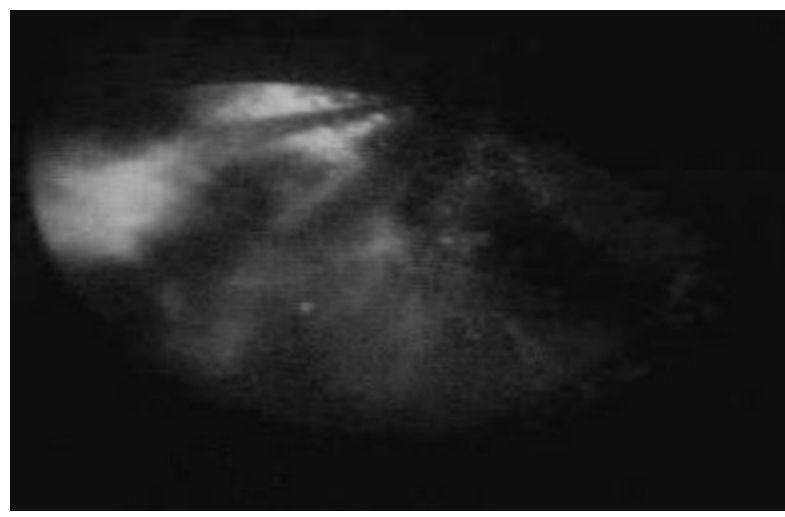

Figure 1: The combustion process in the combustion chamber of a direct injection compression ignition engine.

As far as the combustion process is concerned, the local deficiencies in oxygen constitute a major cause of carbon oxide and hydrocarbons formation. Moreover, the local shortage of oxygen is partially responsible for particulate matter formation, whereas nitrogen oxides formation is mainly connected with the flame development kinetics that account for heat released during combustion. Since the spraying quality and air swirls are firmly correlated with the emissions of carbon dioxide and toxic compounds, fuel mixture pretreatment becomes of paramount importance if the emissions are to be decreased. In order to achieve this goal and produce a more environmentally friendly combustion engine, fuel spraying should be, firstly, analyzed profoundly and later, improved on the basis of the analysis.

To begin with, it is known that the fuel spraying is determined by two critical factors, i.e. the pressure in the nozzle area right before the nozzle hole and the pressure in the combustion chamber where the fuel spray is directed to. Currently, the view that higher injection pressure values improve the fuel spraying is in the injection systems development mainstream. This preferred tendency is quite noticeable as the major advancements have been implemented in the Common Rail (CR) system. Each new generation of this system becomes modified to endure higher and higher injection pressure values $[1,2]$.

However, fuel spraying can be improved not only by means of an increased injection pressure but also by alternations in the mechanism of the fuel spray disintegration into droplets [3-7]. So far the fuel spray disintegration has been realized solely owing to the high velocity of the fuel outflow from the nozzle. 
Yet, the fuel spray may fall apart into droplets more efficiently if fuel-gas solution is formed before supplying the mixture into the combustion chamber. The gaseous phase of the fuel constitutes another critical factor that immensely influences the fuel spraying, and thus the emissions as well as carbon dioxide formation. Therefore it is the purpose of this article to describe and explain the ultimate fuel spraying modification which advances fuel disintegration without rising the injection pressure.

The applicability of the proposed mechanism cannot be evaluated until the physical aspects of the mechanism become exhaustively clarified to provide a firm ground for the engine design modifications. Firstly, the amount of gas that can be dissolved in a liquid, and in the fuel likewise, significantly depends on the pressure of the liquid. A spontaneous release of gas at the non-equilibrium state caused by the liquid pressure is quite typical for such a solution. Secondly, the process of releasing the gas from a liquid is of a volumetric nature, i.e. the gas is being released simultaneously from the whole liquid volume. Finally, as a result, the thermodynamic potency rises so that the gas which is released always has a tendency to break the bonds of liquid molecules. Under such conditions the state of liquid is similar to the state of boiling. The highlighted properties of a liquid are very desirable in the injection system, since fuel displays similar behaviour if mixed with gas. Hence, the concept of using the effervescence effect resulting from releasing gas in fuel has been developed in order to improve the existing mechanism of fuel spraying.

This concept consists in adding the appropriate amount of oxygen to the fuel, then dissolving it under high pressure conditions (in a high pressure pump) and keeping it in a form of solution in a high-pressure section of the engine supply system (up to the nozzle) until the moment of injection as shown in fig. 2. In this case the assumed injection pressure determines the solution thermodynamic potency at which the equilibrium state is achieved.

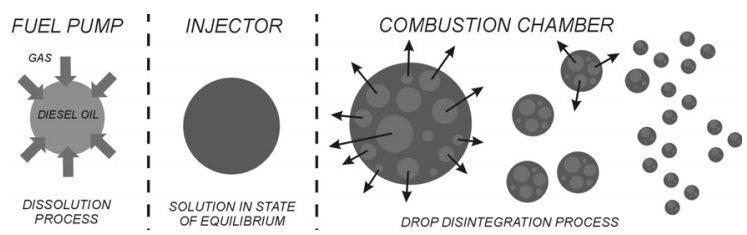

Figure 2: The illustration of a conceived fuel spraying improvement by dissolving gas in fuel $[3,4]$.

In the case of gas-fuel solution, it has to be pointed out that the gas-fuel injection into the combustion chamber causes a sudden pressure drop which entails a serious disturbance of an equilibrium state, and thus, the fuel spray becomes disintegrated due to the gas release in the fuel and the effervescence side-effect. A detailed description of this concept is presented in $[3,4]$. 


\section{Test stand}

The tests were carried out on the engine test stand (fig. 3) equipped with the direct injection compression-ignition test engine AVL 5804. This is a onecylinder engine with a four-valve cylinder head and two camshafts. The injector is situated in the cylinder head centrally in the cylinder axis. The engine had a conceptual supply system of a Common Rail type controlled by SesubCR system. a specially system developed for Common Rail unit electronic control. The test stand had a brake to adjust engine crankshaft speed regardless of the engine load. The test stand also included the lubricating oil and cooling fluid as well as temperature stabilization systems.

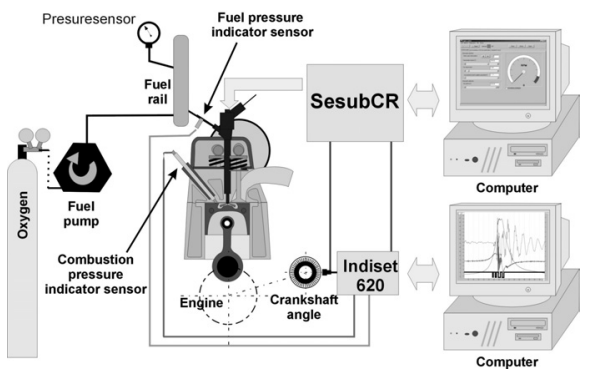

Figure 3: $\quad$ The test stand.

The fuel was supplied to the engine by an accumulator supply system that comprised a supply pump with an independent drive unit. The fuel compressed in the pump was pumped (forced) to the accumulator (a container) called the pressure accumulator from which it was delivered to the BOSCH 0445110131 injector. Its work was controlled by SesubCR system. The relevant injection parameters i.e. the injection start angle and the injection duration time were set by a computer connected with the SesubCR system. In order to perform a correct analysis of the changes in the engine operation parameters it was necessary to fill in the information on the cylinder pressure characteristics just before the injector and also on the characteristics of the pulses controlling the injector operation as a function of the crank angle. For those reasons the engine was equipped with a piezoelectric sensor of the indicated pressure situated in the engine cylinder head just before the injector directly on the injection pipe connecting the injector with the accumulator. The voltage pulses generated by those sensors, after their amplification, and the signal from pulses controlling the work of the injector as well, were sent to the Indiset 620 system provided for recording the quick changing engine processes given in the voltage form. For the comparative nature of the performed examinations it was necessary to use two supply pumps, the conventional one, which barely compresses diesel fuel, and the second one which makes the gas-in-fuel dissolving possible while it is being pumped (forced) (fig. 4). During the investigations the tonnage oxygen taken out from the high pressure oxygen cylinder with the use of the pressure reducing valve was 
used to be dissolved in fuel. Oxygen at the pressure value of 1 and 5 bar was supplied to the forcing section area of the pump through a non-return valve during the piston moving downwards.(fig. 4a). As soon as the piston reveals the lower passage the gas supplying valve closes and the diesel fuel supplying to the fuel forcing section starts (fig. 4b). As soon as the piston moving upwards closes the passage supplying the fuel the compression of the oxygen and diesel fuel in the forcing section starts, during which a gas-in-fuel dissolving process occurs. The liquid solution obtained in this way is pumped (forced) to the fuel accumulator (fig. 4c). From the fuel accumulator it is supplied to the injector, and next to the combustion chamber of the DI engine.

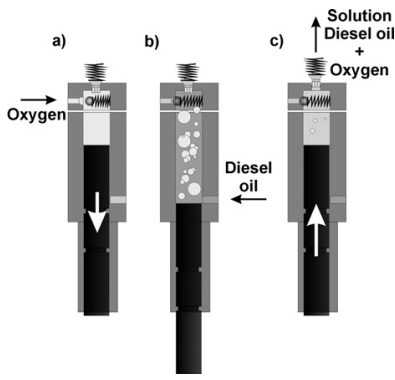

Figure 4: The realisation of the gas-in-diesel fuel dissolving process [3].

The analysis of results obtained in the course of the research required a relevant methodology that had to be developed.

\section{Examination procedure}

The examination was of a comparative nature so it was carried out in two stages. In the first stage the engine was fuelled with diesel fuel and the injection parameters were set as follows:

- $\quad$ the simulated engine speed: $1600 \mathrm{rpm}$;

- $\quad$ the fuel pressure in rail: $\quad 35 \mathrm{MPa}$;

- $\quad$ the duration time of electric pulse opening the injector: $0.95 ; 1.05 ; 1.21$; $1.32 ; 1.49 \mathrm{~ms}$.

In the second research stage the engine was fuelled with diesel fuel -anddissolved oxygen at the same settings of the above injection parameters and the oxygen pressure value in pump: 1 bar.

During the examinations some measurements of the toxic exhaust gas compounds were performed. In each of the set engine operating points the cylinder indicated pressure values, fuel in the injection pipe before the injector, and characteristics of the intensity of the injector opening current values were additionally measured. Those measurements allowed to estimate the similarity of the parameters of the fuel injection realised in each stage of the performed examinations. The obtained parameters were subject to the mutual comparative analysis. 


\section{Test results and discussion}

The evaluation of the discussed conception will be made on the basis of the comparative analysis performed for two groups of values. The first group includes the cylinder pressure value and the rate of the cylinder pressure rise. These quantities are closely connected with the combustion process kinetics. The second group includes the basic components of exhaust gas, the emission of which is subject to the limitation. They are: nitrogen oxides $\mathrm{NO}_{\mathrm{x}}$, carbon oxide $\mathrm{CO}$, hydrocarbons $\mathrm{HC}$ and opacity.

Having realized their research project the authors have gathered extensive comparative material which one cannot help fully presenting here. In this paper only some exemplary results are presented to show the tendencies how the oxygen content in the fuel influences the engine operation observed within the whole research range. These results are presented in a graphic form.

The nature of this impact on the cylinder pressure Pc, characteristic during the combustion process, is shown on a chosen point of engine work in fig. 5. In this figure the fuel pressure characteristics in the high pressure rail $\mathrm{P}$ and the signal $\mathrm{t}$ characteristics are additionally plotted. Owing to the fuel solution and increased mass of oxygen dissolved in it, the compression-ignition delay appears to have a tendency to be shortened. In addition, as the oxygen mass was increasing because of the pressure rise from 1 bar to 5 bars in the pump, the maximal value of pressure in the cylinder was rising too. The courses of both values are illustrated in fig. 6, since they recurred in all examined engine operating conditions.

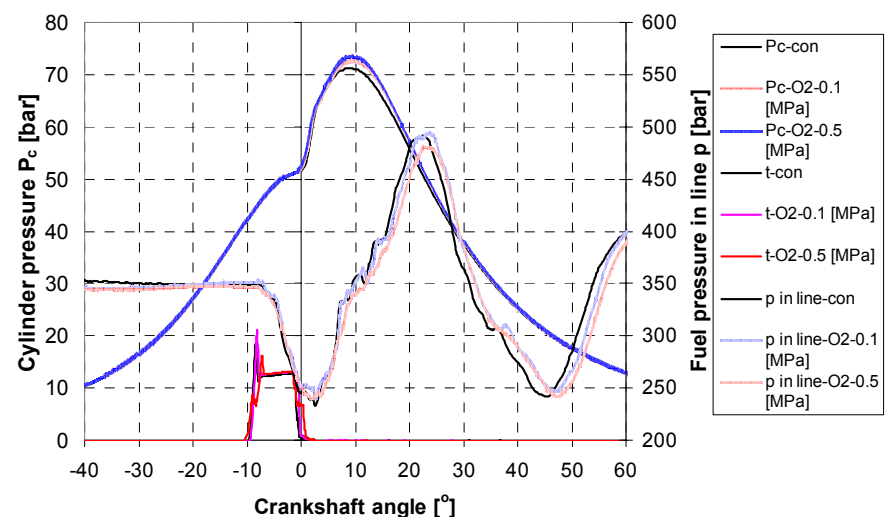

Figure 5: The pressure in the engine cylinder supplied with diesel fuel and diesel fuel with dissolved oxygen; $\mathrm{n}=1600 \mathrm{rpm}, \mathrm{p}_{\text {rail }}=35 \mathrm{MPa}$, $\mathrm{t}=1,32 \mathrm{~ms}$.

The nature of discussed changes is closely connected with the compressionignition delay angle. After adding oxygen to fuel a compression-ignition delay angle is subject to a significant curtailment in comparison to the angle if supplied 
with fuel without oxygen. The extent of the curtailment depends on the amount of oxygen dissolved in fuel and, obviously, on the location of the engine operation point in the general engine characteristics.

Furthermore, the shortened compression-ignition delay angle accounts for the pressure rise rate decrease, distinctly visible in the combustion chamber. At present, it is quite difficult to provide a solid theoretical ground for the interdependence between the increase of oxygen dissolved in fuel and the lower rate of the pressure rise. In the case of supplying oxygen under the pressure of 5 bars the maximal rate of the pressure rise was noticeably decreased.

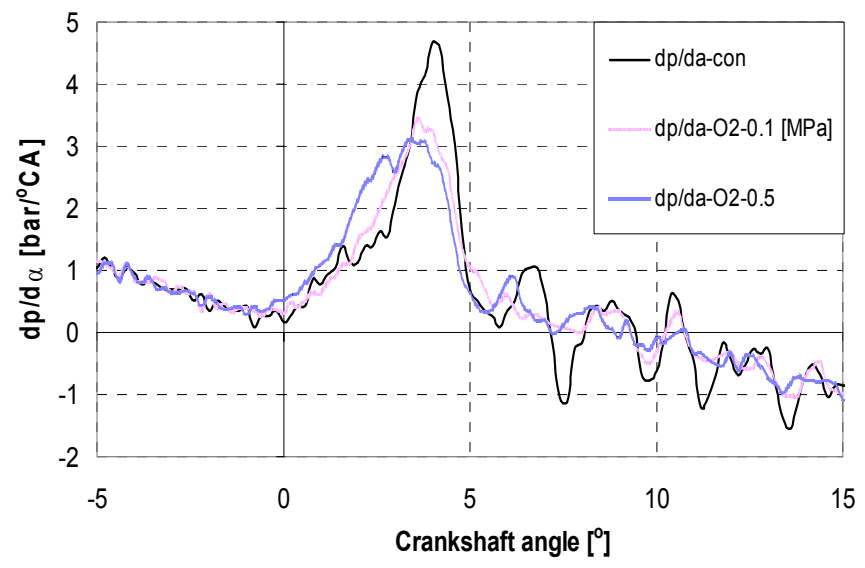

Figure 6: Pressure rise rate in the function of the crank angle; $n=1600 \mathrm{rpm}$, $\mathrm{p}_{\text {rail }}=35 \mathrm{MPa}, \mathrm{t}=1,32 \mathrm{~ms}$.

The improvement of the fuel spray was expected to bring about some positive changes in the aspects of emissions. Therefore, in order to verify the efficiency of the improved fuel spraying mechanism, the amount of toxic compounds released at particular engine operation points if fuelled with fuel-oxygen solution were compared with the emissions caused by the engine fuelled with conventional diesel fuel. The changes in exhaust gas contents as well as toxic compounds concentrations are given in figures 7-10.

On the basis of the comparative analysis, it can be concluded as follows, firstly, better fuel spraying causes a temperature growth which is responsible for intensified $\mathrm{NO}_{\mathrm{x}}$ emissions. $\mathrm{NO}_{\mathrm{x}}$ concentration rose by $25 \%$ at a low engine load. As the engine load increased the concentration decreased and it was $5-17 \%$. However, it was still higher than the concentration measured for the engine fuelled with diesel fuel.

Secondly, although the changes in the case of $\mathrm{NO}_{\mathrm{x}}$ emissions are not presumably desirable, the carbon oxide concentration in exhaust gas almost halved at some points; yet on a global scale, it decreased by $10-40 \%$. Thirdly, the hydrocarbons concentration at particular engine load points diminished by $10-20 \%$. 


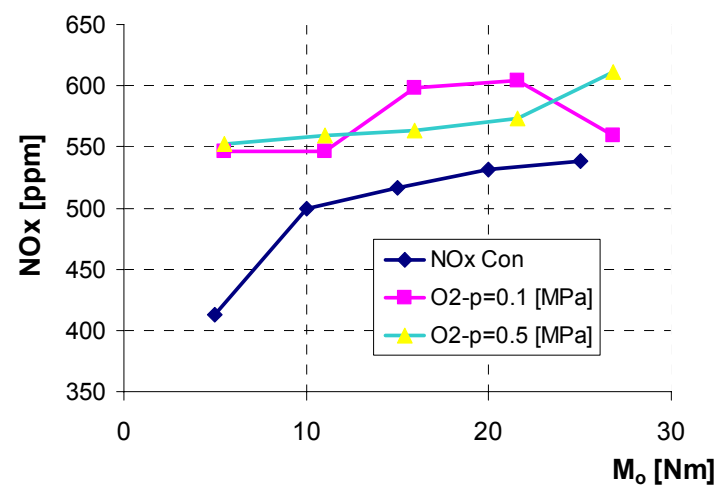

Figure 7: Comparison of the relative changes in the nitrogen oxide concentrations in exhaust gas.

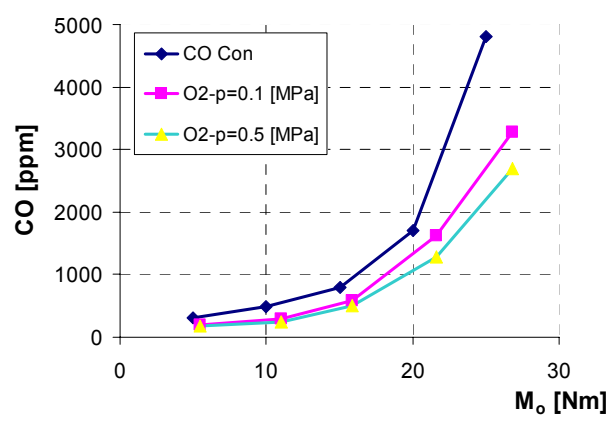

Figure 8: Comparison of the relative changes in the carbon oxide concentrations in exhaust gas.

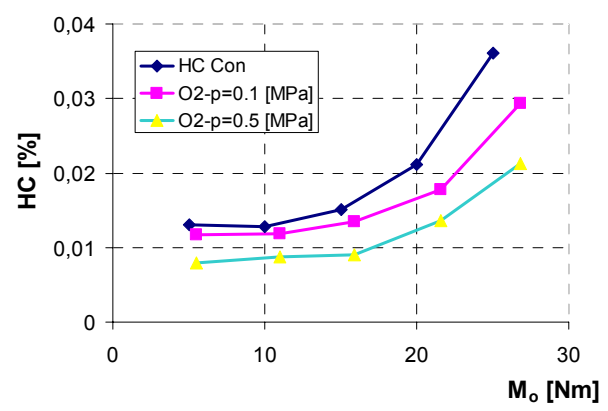

Figure 9: Comparison of the relative changes in the hydrocarbon concentrations in exhaust gas. 


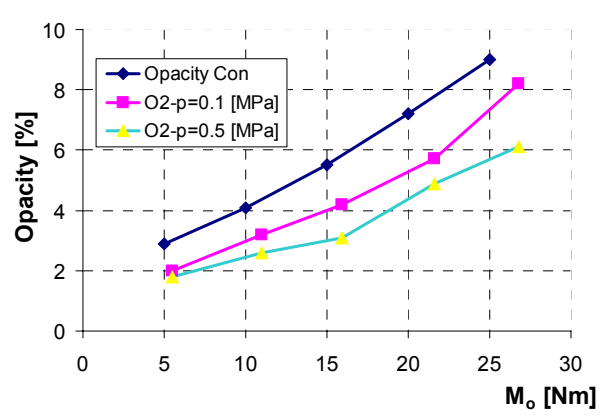

Figure 10: Comparison of the relative changes in the opacity in exhaust gas.

Finally, in comparison to the diesel fuel-based fuelling system (fig. 10), opacity of exhaust gas considerably decreased (in some cases even by $35 \%$ ) in all measurements conducted on the solution-based fuelling system. It is widely known that smokiness indicates the content of soot in exhaust gas to a great extent. Thus, should soot formation mechanism be simplified to cracking, it is possible to draw a conclusion that the liquid fuel phase gives rise to soot. The amount of formulated soot depends on the physical conditions in which hydrocarbon liquid phase is maintained void of air.

\section{Conclusion}

In the light of the presented results, the above-described physical process that provides a theoretical foundation for the new mechanism of fuel spraying can fairly account for the emissions downsizing in combustion engines. Apparently, gas dissolved in fuel, oxygen in this case, improves fuel spraying and indirectly modifies the contents of exhaust gas, especially as far as the toxic compounds and carbon dioxide are concerned. In fact, all main toxic compounds concentrations decreased including the enormous carbon dioxide fall. Furthermore, the temperature growth proves that the fuel disintegration has become more efficient, but it additionally entails $\mathrm{NO}_{\mathrm{x}}$ emissions rise. However, the temperature increase seems to be rather unavoidable at present since Common Rail advancements also cannot help $\mathrm{NO}_{\mathrm{x}}$ formation as the outcome of the temperature growth caused by the increased injection pressure. Nevertheless, one of priorities of automotive advancements in terms of the nature conservation is to diminish not $\mathrm{NO}_{\mathrm{x}}$, but carbon dioxide which is considered to be highly dangerous greenhouse that should be fought against by all means.

\section{References}

[1] Minato A., Tanaka T., Nishimura T.: Investigation of Premixed Lean Diesel Combustion With Ultra-High- Pressure Injection. SAE Technical Paper Series 2005-01-0914. 
[2] List H. O., Cartellieri W. P., "La technologie du Diesel Bases, Etat de l'Art et Perspectives ", Ingenieurs de l'Automobile, Nr 731Aout - Sept. 1999.

[3] Merkisz J., Kozak W., Bajerlein M., Markowski J.: The Influence of Exhaust Gases Dissolved in Diesel Oil on Fuel Spray Particulary Parameters SAE 2007-01-0488, Session: Diesel Fuel Injection and Sprays, SAE World Congress \& Exhibition, 16-19.04.2007, Detroit, Michigan, USA.

[4] Kozak W., Bajerlein M., Markowski J: The application of gas dissolved in fuel with a view to improve the mechanism of spraying. Combustion Engines $\mathrm{Nr} 1 / 2005$ (120).

[5] Heitland H., Rinne G., Kozak W., Wislocki K., Investigations on forming of fuel spray shape in air-assisted fuel injection, Journal of KONES'98, Warsaw-Gdansk, Vol. 5, No 1,1998.

[6] Senda, J., Ohshita, S., Yamamoto, M., Fujimoto, H.: Low Emission Diesel Combustion System by Use of Reformulated Fuel with Liquefied $\mathrm{CO}_{2}$ and n-Tridecane", Proc. 6th Int. Symposium on Marine Engineering, pp.497504, Tokyo, 9-11 September 2000.

[7] Merkisz J., Kozak W., Bajerlein M., Markowski J.: The influence of exhaust gases dissolved in diesel oil on the parameters of CI engine's performance, 31st FISITA World Automotive Congress JSAE, 22-27.10.2006 Yokohama, Japan. 